\title{
Why Do We Need Photovoltaics and Solar Energy? Interrogate an Old Question
}

\author{
Kambiz Hosseinpanahi*, Setayesh Sajjadi \\ Department of Biosystems Engineering, Ferdowsi University of Mashhad, Iran
}

\begin{abstract}
We may have heard multiple times that due to scarcity and reduction of oil and gas resources; it is essential for human beings to turn to renewable energy. Statistics and figures are also mentioned to express this issue, which shows how vital this global concern is. But is the compensation of fossil resources the only reason for changing our approach through renewable energies, especially solar and photovoltaic, or is there other motivation for this? If we had hundreds of centuries or even more time to access the sources of fossil fuels, would our view against solar energy, especially photovoltaic, remain the same? In this article, we intend to address the importance of photovoltaic energy and the need for this permanent existing energy resource from another perspective. It seems that the main motivator of this matter is modernity, development, and its consequences that force human beings to adapt themselves with them. In this study, we explain the importance of the development in the photovoltaic field in today's modern world and justify politicians and people to develop and use this type of energy. In fact, we need renewable energy, especially photovoltaics, to survive and thrive.
\end{abstract}

Keywords: Renewable Energies, Solar Energy, Modernity, Development, Utopia

\section{Introduction}

Today, there are almost no people who do not know much about renewable energy, especially photovoltaics and solar energy. We all know that the sun is one of the cheapest, cleanest and most permanent resources that can be used in any geographical climate and is therefore the most popular among other renewable energies. You may also have heard that the reason for using this renewable energy source is the lack of fossil fuel sources. Undoubtedly, the lack of fossil fuel resources is a major reason that you have heard over and over again. But this is no longer enough for our world today, and there are other reasons for the importance of using photovoltaics that are becoming more and more important. In the past, the sole purpose of developing photovoltaics and solar energy was to replace it with fossil fuel sources, so researchers only thought of increasing efficiency, and the best solar cell was the one with the highest efficiency. Although this goal remains, but in recent decades other important parameters have emerged that have doubled the importance of this issue. As in the past, high efficiency alone is no longer enough, today, transparency, flexibility, low weight, etc. are other parameters that are very important; Because at present, in addition to high efficiency, these parameters are also very important for the use of photovoltaic technologies in modern urban 
places (Kuhn et al., 2020). For example, if we cover all the roofs suitable for installing solar panels in the United States with photovoltaic cells with a efficiency of $16 \%$, we can generate approximately $40 \%$ of the total energy produced in the United States in this way. Now imagine if, instead of a roof, the entire surface of a building, including walls and windows, could be covered with transparent, flexible, photovoltaic cells compatible with urban space and modern architecture Even with efficiencies below 16\%, how much of the electricity needed by cities can be generated by this way? (Traverse et al., 2017; US Energy Information Administration, 2012; US Energy Information Adminstration, 2009). On the other hand, the urgent need for electricity in cities makes a permanent source of energy, clean and compatible with modern urban space and modernity standards such as photovoltaics more important than any other source. With these explanations, we realize the importance of this issue that today there are other reasons for the development and need for photovoltaics and it is not only the lack of fossil fuel sources that stimulates the spread of solar energy but also its compatibility with modern urban space and modernity standards and its constant production of electricity that is used in cities. Understanding and explaining this issue can justify managers, politicians and even people that the importance of the development of solar energy, especially photovoltaics, is necessary and should be viewed from another perspective. This view is important even in countries with vast oil, gas, and coal resources, because with fossil fuel sources now available, there is no inclination for widespread photovoltaic development among politicians and even the public. But when this is seen from a different perspective, then it can be more easily mentally justified for people to accept that photovoltaics and solar energy need to be further developed.

If we look more closely at this issue, we find that it is due to the definition of new applications and needs in the modern world that in addition to high efficiency, the parameters of transparency, flexibility, low weight, etc. have become important. In fact, modernity is the driving force behind the spread and need for photovoltaic energy in today's world. It was also because of the modernization of societies that technology grew day by day and as a result the need for energy was felt more and more. The unprecedented increase in energy consumption, especially fossil fuels, in recent decades is due to this issue (Figure 1). On the other hand, this increase in energy consumption has caused irreparable problems and incidentally is one of the reasons for the development of photovoltaics to solve these problems. Accordingly, in this article, we try to take a brief look at this issue and why it is, and this time ask ourselves a recurring and old question from another perspective? Why do we need renewable energy, especially photovoltaics? 


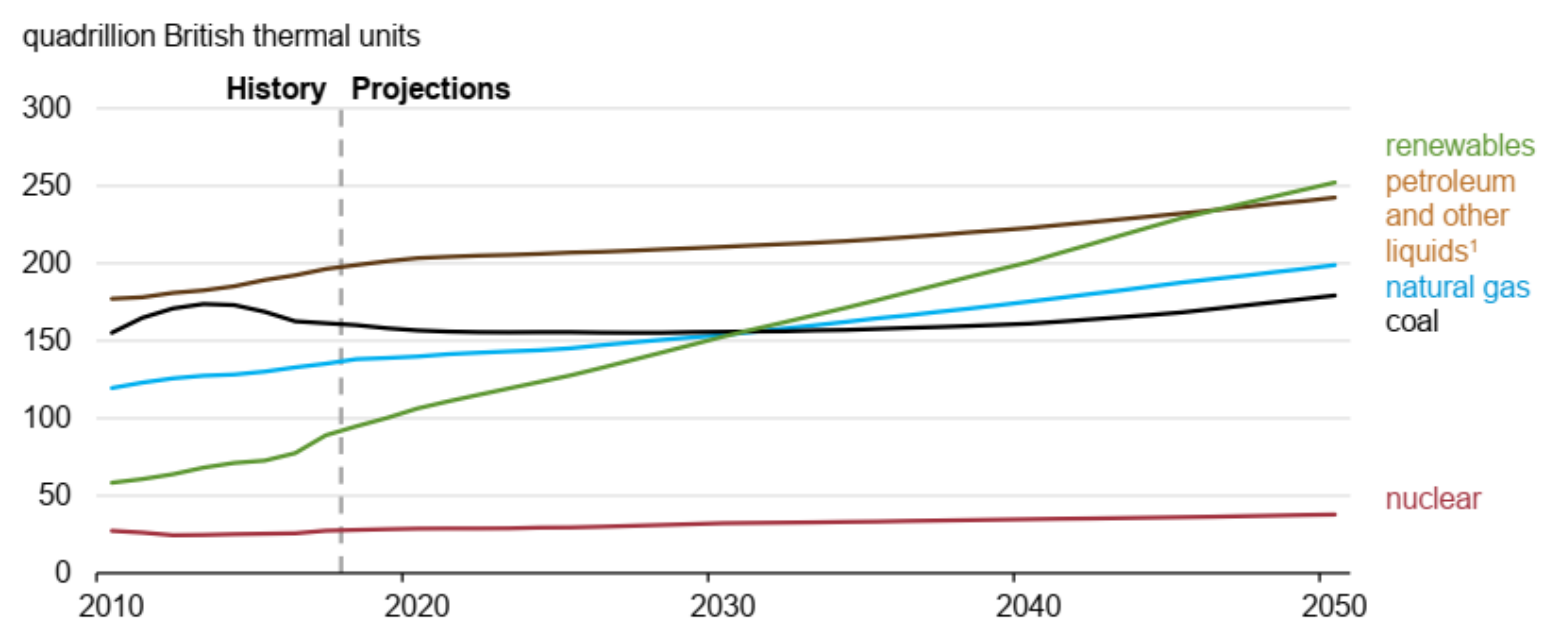

Note: 1 = Includes biofuels

Source: U.S. Energy Information Administration, International Energy Outlook 2019

Figure 1: Primary energy consumption by fuel in the world. The data show that the amount of energy consumption is increasing every year compared to the previous year (IEA (2020), 2020).

\section{Modernity, human development Index (HDI) and energy}

New era, modern era or modernity, refers to the new (modern) society. Modernity is a historical period that covers the period between the fifteenth century and the twentieth century and is a multitude of cultural and intellectual movements (Berman, 1983; Hollan and McLean, 1998). But from a scientific and technological point of view, modernity is a process by which societies, using the latest scientific and technological achievements, reach new areas of prosperity and economic, social and environmental sustainability. On the other hand, human history is intertwined with technological developments. Man has willingly or unwillingly been on the path of technological development and has brought with it human well-being and prosperity. Without technology today, such a position would not have been conceivable for human beings. With the development of modernity, we have faced several waves of the emergence of technology; From the Industrial Revolution and the invention of the steam engine to the present day when the Internet and space travel are expanding, they have all included different types of technology that have been the result of modern thinking and the modern lifestyle.

Modernity itself can be examined from several perspectives. From a philosophical, social, cultural, technological and technical point of view, the achievement of which has been a modern and advanced society that has led to human development. There are various indicators to show the degree of development and modernity of societies, one of the most important of which is an indicator called the Human Development Index. This index is a method for measuring success in any country, in three basic criteria of human development: life expectancy, education and per capita income indicators (Stanton, 2007). The higher the human development index of a society, the closer the living conditions in that society are to their ideal form. Usually, countries that have a higher level of human development index have a higher level of development and are called developed countries (Figure 2). But on the other hand, 
efforts to improve development and the human development index have requirements, one of the most important of which is energy. In fact, the stimulus of a large part of this great movement of development is the urgent need for energy, which in case of any disruption in its supply, practically very large parts of human societies will face closure and deadlock. A small part of this can be seen in history, whenever the price of oil and gas rises or the transfer of these important energy resources is disrupted due to political problems between countries, it has caused irreparable damage (Singer, 2008). Therefore, one of the essential needs for development is the need for energy. But this needs for energy and the effort to provide it in order to prevent the stagnation of human development has caused major problems in the world. The consequences of this human endeavour have turned these problems into a threat. Problems that have challenged human life and the environment as well as other essential resources (Kazim, 2007; Wang, 2010).



Fig 2. a) World map of countries or territories by Human Development Index scores in increments of 0.050 (based on 2019 data, published in 2020) $\geq 0.900|0.850-0.899 \quad 0.800-0.849| 0.750$

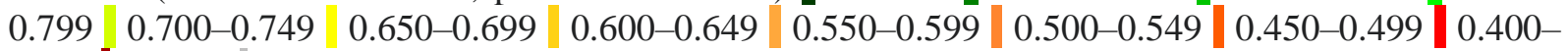
$0.449 \leq 0.399 \mid$ Data unavailable (UNITED NATIONS DEVELOPMENT PROGRAMME, 2020). The data from the map show that in practice, countries with higher development rates also have higher human development indexes.

\section{Development and electricity}

Among the types of energy, electricity is the energy that human beings urgently need to further develop and expand the frontiers of knowledge. Studies show that the more developed a country is, the higher its electricity consumption (Figure 3); Because electricity is apparently a clean, noise-free and pollution-free energy that is very easy to use. Home appliances to computers, cell phones and many other modern devices need electricity. A simple example is 
the Internet and social networks. For a simple internet search, access to a messenger, or a social network that has become an integral part of today's societies and is expanding every day, you need electricity. In fact, electricity is the soul of today's technology. There are various methods for supplying electricity, the main of which is electricity generation by hydropower or in conventional power plants dependent on fossil fuels (Hall and Bain, 2008). There are other methods, such as the use of renewable energy, which if we look at the production of electricity in this way in all countries, we find that its share in the production of electricity is small (IEA (2020), 2020). Conventional methods of generating electricity directly and indirectly have created major problems, the most important of which include environmental problems and the destruction of human and animal ecosystems. The devastation that has become a potential threat around the world today. Global warming, groundwater and surface water pollution and consequently endangering food safety and health are among the most important consequences of this degradation (Wang, 2010). The emergence of these problems has led the United Nations to formulate 17 goals for the creation of an ideal human society (UN, 2020) and the efforts of all its organs and even some developed countries to fulfill these ideals. Healthy environment, health, healthy food and renewable energy are among these 17 goals and show the importance of this discussion.

Because of these problems, developed countries are looking for a way to expand their renewable energy sources so that they can gradually supply all or much of their electricity. Most of this energy is consumed today in cities and modern urban space, so that approximately $75 \%$ of energy resources are consumed annually in cities (Chowdhury et al., 2019). If the renewable energy plant is located in the same space and can adapt to today's modern space, it can have a tremendous effect in reducing the problems that have arisen, especially environmental problems. The modern ideal human space is a space in which, in addition to advancing human development and raising the level of human technology, it must have no or the least negative and destructive effect. In the meantime, photovoltaics and especially its new generations can play a very important role in advancing this important and that is why in addition to efficiency, other important parameters such as transparency, flexibility and low weight are very important. On the other hand, the emergence of new applications in modern societies has led researchers in the field of photovoltaics to develop a type of photovoltaic cell and a specific type of technology for each application. Establish a balance depending on the application. Because sometimes a cell with relatively low efficiency but due to other appearance capabilities can be much more efficient than a high-efficiency photovoltaic cell alone. 

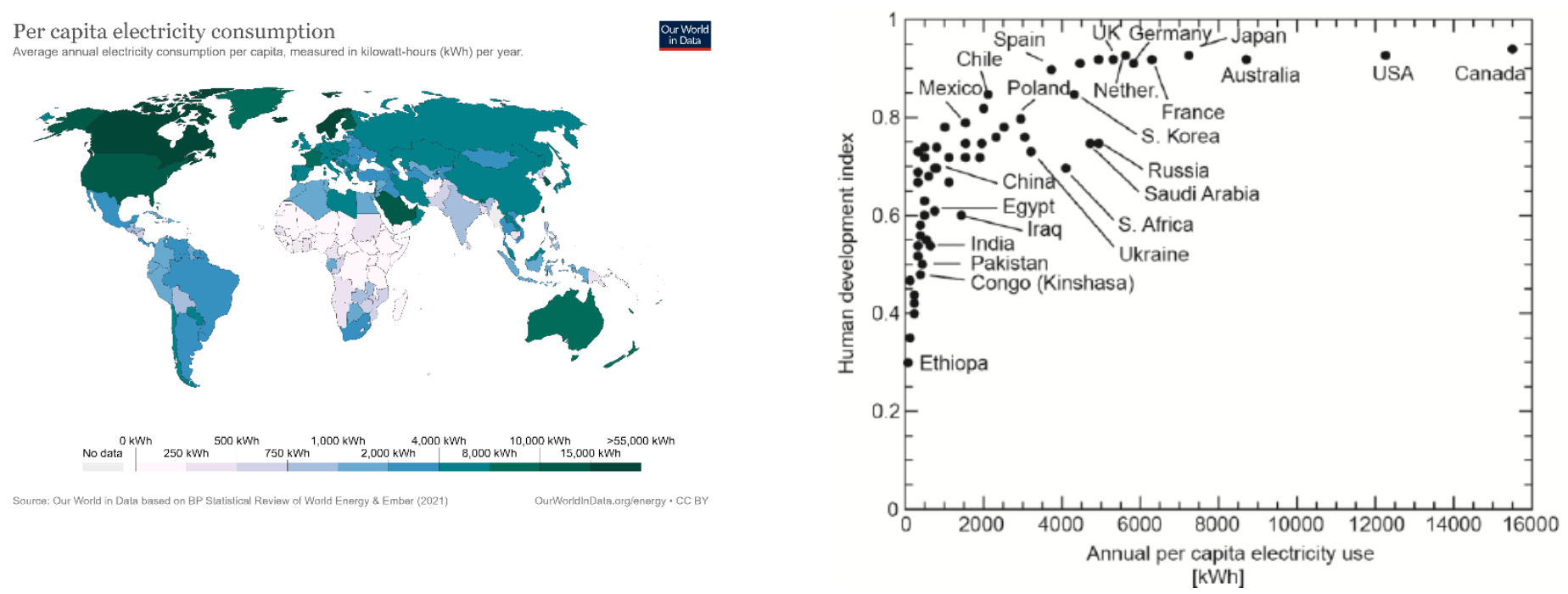

Fig 3. a) Average annual electricity consumption per capita, measured in kilowatt-hours (kWh) (Our World in Data, 2020). b) Relationship between countries with different human development index and electricity consumption (Hegedus and Luque, 2003). Comparison of Figures 3-a (left pic) and 3-b (right pic) and Figure 2 shows that the higher the level of development as well as the human development index, the higher the electricity consumption.

\section{Conclusion}

If we review the above once again, we will see that the modern urban space and the lifestyle of modernity have an urgent need for energy, especially electricity. On the other hand, modern and so-called developed lifestyle has requirements that must be observed. The best case scenario is to develop in a situation where it has no or minimal destructive effect. This destructive effect can be environmental pollution, noise pollution, destruction of human and animal ecosystems, etc. Aesthetic issues are also one of the requirements of modernity. Every external parameter that enters the modern space and place should not only take its soul but should also be effective in conveying its meaning. Considering all these factors, it is necessary to have an energy source that has all these criteria as much as possible. Among the types of energy sources, renewable energies and among them solar energy, especially photovoltaics, have the highest compatibility with these criteria. Therefore, it should be noted that one of the main reasons for the development of photovoltaics in today's world is not only to compensate for the lack of fossil resources, but also the compatibility of energy sources with the concept and standards of modern life and this issue should be considered in policy and culture and this time it is better to look at renewable energies, especially photovoltaics, from this perspective and develop with this perspective.

\section{Acknowledgment}

This paper was supported by Ferdowsi University of Mashhad (FUM). 


\section{References}

Berman, M., 1983. All that is solid melts into air: The experience of modernity. Verso.

Chowdhury, P.K.R., Weaver, J.E., Weber, E.M., Lunga, D., St Thomas, M.L., Rose, A.N., Bhaduri, B.L., 2019. Electricity consumption patterns within cities: application of a datadriven settlement characterization method. International Journal of Digital Earth.

Hall, P.J., Bain, E.J., 2008. Energy-storage technologies and electricity generation. Energy policy $36,4352-4355$.

Hegedus, S.S., Luque, A., 2003. Status, trends, challenges and the bright future of solar electricity from photovoltaics. Handbook of photovoltaic science and engineering, 1-43.

Hollan, D., McLean, G.F., 1998. National, Cultural, and Ethnic Identities: Harmony Beyond Conflict. CRVP.

IEA (2020), 2020. Renewables 2020. IEA, Paris.

Kazim, A.M., 2007. Assessments of primary energy consumption and its environmental consequences in the United Arab Emirates. Renewable and Sustainable Energy Reviews $11,426-446$.

Kuhn, T.E., Erban, C., Heinrich, M., Eisenlohr, J., Ensslen, F., Neuhaus, D.H., 2020. Review of technological design options for building integrated photovoltaics (BIPV). Energy and Buildings, 110381.

Our World in Data, 2020. Per capita electricity consumption, 2020.

Singer, C.E., 2008. Energy and international war: From Babylon to Baghdad and beyond. World Scientific.

Stanton, E.A., 2007. The human development index: A history. PERI Working Papers, 85.

Traverse, C.J., Pandey, R., Barr, M.C., Lunt, R.R., 2017. Emergence of highly transparent photovoltaics for distributed applications. Nature Energy 2, 849-860.

UN, 2020. 17 Goals to Transform Our World.

UNITED NATIONS DEVELOPMENT PROGRAMME, 2020. Human Development Reports.

US Energy Information Administration, 2012. Commercial Buildings Energy Consumption Survey (CBECS) Data.

US Energy Information Adminstration, 2009. Residential Energy Consumption Survey (RECS) Data ().

Wang, Y., 2010. The analysis of the impacts of energy consumption on environment and public health in China. Energy 35, 4473-4479. 